Bio - grafia. Escritos sobre la Biología y su Enseñanza. ISSN 2027

Edición Extraordinaria. p.p. $1102-1112$

Memorias del VIII Encuentro Nacional de Experiencias en Enseñanza de la Biología y la Educación Ambiental. III Congreso Nacional de Investigación en Enseñanza de la Biología.

\title{
Contribuições do Ensino de Bioquímica na Formação Inicial de Professores em Ciências Biológicas e sua Relação com a Educação Básica
}

\section{Contributions of Biochemistry Teaching in the Initial Training of Biological Sciences Teachers and their Relation to Basic Education}

\author{
Aportes de la enseñanza de Bioquímica en la formación inicial del profesorado de \\ ciencias biológicas y su relación con la educación básica
}

Eva Teresinha de Oliveira Boff, Maria Cristina Pansera-de-Araújo e Vidica Bianchi

Departamento de Ciencias da Vida - Universidade Regional do Noroeste do Estado do Rio Grande do Sul -Unijui

Resumo $O$ conhecimento biológico atual é marcado pela crescente interrelação entre várias subáreas, que o constituem. Os avanços educacionais exigem dos professores uma conduta cada vez mais qualificada. Portanto, objetiva-se compreender a contribuição da Bioquímica na formação do professor de Ciências e Biologia e sua relação com a Educação Básica. Para tanto, foram realizadas análises documentais das ementas, do conteúdo programático e das referências, presentes nos planos de ensino dos componentes de Bioquímica I e II. As percepções dos licenciandos foram analisadas num diálogo reflexivo com a proposta metodológica das professoras universitárias, como modo de contribuição para formação docente. Além disso, foi possivel identificar um alinhamento entre as ementas, conteúdos programáticos com os sumários dos livros didáticos do Ensino Superior. Embora estes livros descrevam os conteúdos de bioquímica de forma linear, sem relação com situações do contexto dos estudantes, a metodologia de ensino utilizada na licenciatura permite a superação do ensino fragmentado e o estabelecimento de relações com a educação básica possibilitando a significação do sistema conceitual da área.

Palavras-chave: Ensino de Bioquímica, Formação Docente, Livro Didático

Resumen: El conocimiento biológico actual está marcado por el enlace creciente entre las distintas subáreas que lo constituyen. Los avances educacionales exigen de los profesores una conducta cada vez más calificada. Por lo tanto, comprender la contribución de la bioquímica en la formación del profesor de biología y su relación con la Educación Básica es el objetivo de este artículo. De este modo, fueron realizadas análisis documentales de los 
Bio - grafia. Escritos sobre la Biología y su Enseñanza. ISSN 2027

Edición Extraordinaria. p.p. 1102- 1112

Memorias del VIII Encuentro Nacional de Experiencias en Enseñanza de la Biología y la Educación Ambiental. III Congreso Nacional de Investigación en Enseñanza de la Biología.

planes de estudios, de los contenidos programáticos y de la bibliografía de referencia presentes en los planes de enseñanza de las asignaturas de Bioquímica I y II. La percepción de los alumnos fue analizada a partir de un dialogo reflexivo con la propuesta metodológica de las profesoras universitarias, como forma de contribución para la formación docente. Además, fue posible identificar una conexión entre los planes de estudios, contenidos programáticos y sumarios de los libros didácticos de la enseñanza universitaria. Aunque estos libros traten de los contenidos de bioquímica de manera fragmentada y sin conexión con el cotidiano de los estudiantes, la metodología utilizada en la enseñanza universitaria permite la superación de la educación fragmentada y la construcción de relaciones con la educación básica, posibilitando la significación del sistema conceptual del campo de estudio.

Palabras clave: Bioquímica de enseñanza, formación del profesorado, libros de texto

Abstract The current biological knowledge is marked by the growing interrelationship between various sub-areas, which constitute them. Educational advances require teachers conduct increasingly qualified. Therefore, the objective is to understand the contribution of Biochemistry in teacher education of science and biology and its relation to basic education. Therefore, desk reviews of the subjects' presentations were held, the curriculum and references, presented in the teaching plans of the components of Biochemistry I and II. The perceptions of undergraduates were analyzed in a reflective dialogue with the methodological proposal of university teachers as a contribution to teacher training. Moreover, it was possible to identify an alignment between the presentations and syllabus with the summaries of textbooks of Higher Education. Although these books describe the linearly biochemistry content, unrelated to the context of situations of students, the teaching methodology used in the graduation allows the overcoming of fragmented education and the establishment of relations with basic education enabling to mean the science's conceptual system.

Keywords: Biochemistry Teaching, Teacher Training, Textbook.

\section{Introdução}

O conhecimento biológico atual é marcado pela crescente inter-relação entre várias subáreas, tais como biologia e genética molecular, imunologia, microbiologia, bioquímica e bioética, que ampliam os estudos da biodiversidade de bactérias, fungos, protozoários, plantas e animais, nas suas interações intra $e$ interespecíficas. $O$ fato do ser humano 
Bio - grafia. Escritos sobre la Biología y su Enseñanza. ISSN 2027

Edición Extraordinaria. p.p. 1102- 1112

Memorias del VIII Encuentro Nacional de Experiencias en Enseñanza de la Biología y la Educación Ambiental. III Congreso Nacional de Investigación en Enseñanza de la Biología.

transformar o meio, em que vive, provoca preocupações em relação aos problemas que tal influência pode exercer sobre a continuidade da vida no planeta. Krasilchik \& Trivelato (1995) apontam que o ensino de biologia deverá propiciar que cada indivíduo seja responsável pelo seu bem estar e, ainda, seja capaz de tomar decisões fundamentadas em conhecimentos cientificamente validados e fornecidos pela escola, conforme o momento sócio-histórico-cultural em que está inserido. Neste sentido, a formação do professor nos cursos de licenciatura no contexto do debate sobre uma educação de qualidade vem adquirindo cada vez mais espaço na sociedade brasileira, numa perspectiva da complexidade e aprimoramento do ensino das diversas Ciências. A lei de Diretrizes e Bases da Educação Nacional (BRASIL, 1996) expressa a urgência de reorganização do ensino, para contemplar os desafios impostos pelos processos globais e pelas mudanças sociais e culturais geradas. Impõe-se a busca da superação da fragmentação do ensino e constituir o estabelecimento de relações, que permitam a produção de aprendizagens efetivas para interpretar $e$ intervir na realidade social e cultural, que os estudantes vivenciam.

Além disso, os PCN+ (BRASIL, 2006) colocam que os conteúdos devem propiciar condições para o educando entender a vida como manifestação de sistemas organizados e integrados, em constante interação com o ambiente Biológico, Físico e Químico.

Assim, a contribuição dos componentes de conhecimento específico e pedagógico para a formação do licenciado em Ciências Biológicas é tema de estudo de professores da Licenciatura em Ciências Biológicas de uma universidade brasileira do interior do Estado do Rio Grande do Sul.

Os licenciandos ao final de seu curso desenvolvem um trabalho de sistematização do curso de modo a refletir sobre as práticas, conteúdos e metodologias vivenciados neste período de formação inicial. Analisam as ementas, conteúdos programáticos e metodologias dos componentes, buscando compreender o processo de organização do projeto pedagógico do curso $e$ as relações com a educação básica. Neste texto objetiva-se compreender a contribuição da Bioquímica na formação do professor de Biologia e sua relação com a Educação Básica.

\section{Metodologia}

Foram realizadas análises documentais do Projeto Pedagógico do curso de Licenciatura em ciências Biológicas, das ementas e conteúdo programático dos componentes de Bioquímica I e II, suas referências e abordagens em Livros Didáticos de Biologia do Ensino Médio. Os dados referentes aos diálogos foram obtidos a partir de registros dos diários de bordo dos 
Bio - grafia. Escritos sobre la Biología y su Enseñanza. ISSN 2027

Edición Extraordinaria. p.p. 1102- 1112

Memorias del VIII Encuentro Nacional de Experiencias en Enseñanza de la Biología y la Educación Ambiental. III Congreso Nacional de Investigación en Enseñanza de la Biología.

professores e estudantes, em formação inicial docente, envolvidos nos componentes curriculares de Bioquímica I, II e Trabalho de Sistematização no Ensino de Biologia (TSEB) do Curso de Licenciatura em Ciências Biológicas, de uma universidade brasileira. $O$ componente TSEB visa sistematizar as atividades desenvolvidas no decorrer do curso, na perspectiva de discutir, com os estudantes, as contribuições dos diferentes componentes curriculares da graduação e sua relação com a educação básica. A Análise Textual Discursiva (ATD) de Moraes e Galliazi (2007) é importante porque possibilita análise do conteúdo bem como do discurso a partir de um movimento fragmentação/desconstrução dos textos e a unitarização. Do confronto das unidades de significado, é possível constituir as categorias de análise e o metatexto.

\section{Resultados e Discussão}

A formação inicial para o ensino de Ciências no nível Fundamental e Biologia no Ensino Médio realizada na Licenciatura em Ciências Biológicas é focada desde a análise do Projeto Pedagógico do curso (PPC) e de diferentes documentos que regem e regulamentam a organização do mesmo.

O Projeto Pedagógico do Curso de Licenciatura em Ciências Biológicas habilita o docente para atuar no ensino de Ciências e Biologia na Educação Básica (BIOLIC - Unijui, 2007). É constituído por componentes perfazem 184 créditos em 2960 horas, a serem cursados em 8 semestres, que visa

[...] formar Biólogos familiarizados com as exigências relacionadas ao exercício do Magistério na Educação Básica e Superior, competentes para 0 estudo aprofundado da origem, organização e diversidade de seres vivos, da relação deles entre si e com o ambiente, além dos processos e mecanismos biológicos que regem a sua formação, desenvolvimento, reprodução e envelhecimento. Além disso, a compreensão desses conceitos e do reconhecimento de que a população humana mundial está envelhecendo, impõe um status próprio, que coloca a Biologia como parte e fundamento das ações em Saúde, entendida como o bem estar físico, psicológico, social e cultural. Então, esse curso inscreve-se nessa área ao criar condições de tratar de forma mais ampla as relações entre os seres vivos de modo a minimizar os resultados do impacto ambiental da espécie humana sobre o planeta 
Bio - grafia. Escritos sobre la Biología y su Enseñanza. ISSN 2027

Edición Extraordinaria. p.p. 1102- 1112

Memorias del VIII Encuentro Nacional de Experiencias en Enseñanza de la Biología y la Educación Ambiental. III Congreso Nacional de Investigación en Enseñanza de la Biología.

como um todo e, em especial, sobre si mesma (BIOLIC-UNIJUI, 2007, p. 2)

O conhecimento biológico específico expresso no PPC de Licenciatura em Ciências Biológicas (BIOLIC-UNIJUI, 2007) está distribuído em componentes de 6, 4 e 2 créditos, sendo que um crédito equivale a 15 horas (Quadro 1).

Quadro 1: Total de créditos por componente curricular de conhecimento especifico do PPC BIOLIC-Unijui 2007

\begin{tabular}{|l|l|}
\hline Horas/cred & \multicolumn{1}{|c|}{ Componente Curricular } \\
\hline $90-6$ & Zoologia I \\
\hline $60-4$ & $\begin{array}{l}\text { Bioestatística; Física para Biologia; Química Geral; Biologia Celular; } \\
\text { Imunologia; Química para Biologia; Botânica I, II e III(cada uma } \\
\text { delas); Embriologia; Bioquímica I e II(cada uma); Zoologia II e III } \\
\text { (cada uma); Microbiologia; Biologia Tecidual; Ecologia; Anatomia } \\
\text { Humana; Fisiologia Animal; Genética I e II(cada uma); Fisiologia } \\
\text { Vegetal; Fisiologia Humana e Evolução }\end{array}$ \\
\hline $30-2$ & Imunologia, Biofísica, Geologia e Paleontologia \\
\hline
\end{tabular}

A área de Bioquímica integra os conhecimentos de química e biologia, visando compreender os processos químicos envolvidos em nível celular, e no curso está distribuído em dois componentes Bioquímica I ( $3^{\circ}$ semestre) e a Bioquímica II ( $4^{\circ}$ semestre). A organização e a sequência de conteúdos do componente curricular são importantes porque organizam 0 processo de aprendizagem de modo evolutivo. Assim, na bioquímica I os estudantes iniciam identificando a constituição dos seres vivos, em nível molecular, mas com o uso da palavra em diferentes contextos. Na medida em que as palavras vão sendo utilizadas adquirem novos sentidos sempre evoluindo para a produção de significados mais complexos de modo a estabelecer o sistema conceitual da área. $O$ quadro 2 mostra as ementas, conteúdos programáticos e referencias dos componentes Bioquímica I e II.

Quadro 2. Ementas e conteúdos programáticos da Bioquímica I e da Bioquimica II do curso de Licenciatura em Ciências Biológicas Unijui 2007. 
Bio - grafia. Escritos sobre la Biología y su Enseñanza. ISSN 2027

Edición Extraordinaria. p.p. 1102- 1112

Memorias del VIII Encuentro Nacional de Experiencias en Enseñanza de la Biología y la Educación Ambiental. III Congreso Nacional de Investigación en Enseñanza de la Biología.

\section{COMPONENTE CURRICULAR: Bioquímica I}

EMENTA: $O$ ensino de Bioquímica I visa o entendimento da estrutura química, propriedades e funções biológicas de moléculas que estruturam e fornecem energia para um organismo vivo. Visa explicar a forma que as diferentes moléculas interagem entre si e com o meio, a partir da aplicação de diferentes métodos experimentais, de identificação e caracterização dos principais componentes químicos da matéria viva, relacionando eventos bioquímicos a nível celular com processos fisiológicos que ocorrem nos seres vivos.

\section{Conteúdo Programático}

1) Bioquímico $\times$ profissional de biologia; 2) Carboidratos; lipídios; aminoácidos; proteínas; enzimas;3) Nucleosídios, nucleotídios e derivados dos nucleotídeos; 4) Vitaminas; 5) Água e Sais Minerais

\section{COMPONENTE CURRICULAR: Bioquímica II}

Ementa: $O$ ensino de Bioquímica II visa o estudo do metabolismo celular de forma que contemple as diferentes rotas metabólicas envolvendo os processos que fornecem energia para os organismos vivos. Visa explicar a forma que as diferentes rotas se inter-relacionam fisiologicamente e quimicamente nos diferentes tipos de organismos vivos.

\section{Conteúdo Programático}

1) Metabolismo; 2) Metabolismo dos carboidratos: destino, via glicolítica, destino aeróbico e anaeróbico do piruvato, Ciclo do ácido cítrico; cadeia transportadora de elétrons e Fosforilação oxidativa e seus inibidores e desacopladores, Radicais livres, lançadeira de elétrons, entrada da maltose, galactose e frutose na via glicolítica, via das pentoses, glicogenólise, glicogênese e gliconeogênese; regulação e integração do metabolismo dos carboidratos; 3) Metabolismo dos lipídeos; 4) Metabolismo dos aminoácidos; 5) Erros inatos do metabolismo; 6) Integração e regulação hormonal do metabolismo energético dos mamíferos. 
Bio - grafia. Escritos sobre la Biología y su Enseñanza. ISSN 2027

Edición Extraordinaria. p.p. 1102- 1112

Memorias del VIII Encuentro Nacional de Experiencias en Enseñanza de la Biología y la Educación Ambiental. III Congreso Nacional de Investigación en Enseñanza de la Biología.

Os conhecimentos científicos construídos pelos licenciandos desde as metodologias de ensino utilizadas pelo professor em cada componente, em suas particularidades até 0 processo avaliativo instituído, constituem a especificidade da formação profissional.

Do mesmo modo, a relação de conteúdos apresentada, remonta uma sequência que se complexifica à medida que se avançam nos domínios dos conceitos, também contribui para produção de concepções de ensino pelos licenciandos. Emerge aí o papel central do professor como mediador dos saberes constituídos nos livros didáticos e os modos de melhorar as aprendizagens dos seus alunos. Os livros didáticos de educação básica apresentam a mesma lógica que os do Ensino Superior, porém, com maior profundidade e comprometimento científico. Por exemplo, nos livros de educação básica, na área da citologia, os componentes químicos da célula estão organizados em um capítulo sobre mitocôndrias e respiração celular. Já no ensino superior, a composição química da célula e suas organelas, na disciplina de bioquímica é abordada para compreender como ocorrerão os processos metabólicos, anabolismo e catabolismo. Esses conceitos são indispensáveis para entender como se processa o metabolismo das diferentes substâncias dentro da célula e cabe ao professor problematizar estas questões junto com seus alunos para que produzam novos sentidos e significados para tal abordagem.

Já, a parte destinada à nutrição em anatomia e fisiologia comparada dos animais não trata os aspectos fundamentais da bioquímica, trazendo muitos "nomes" e pouca identificação/integração com sua classificação (proteínas, lipídios, glicídios, vitaminas), o que seria importante para a compreensão do organismo de maneira integrada. Krasilchik \& Trivelato questionam:

Que ser humano cabe no ensino de Biologia? A primeira consideração que me ocorre na tentativa de responder a tal pergunta é que há um problema de tamanho para incluir o corpo humano no ensino de biologia. (...) o ser humano cabe, no ensino, apenas aos pedaços. (KRASILCHIK \& TRIVELATO, 2005 p. 122)

A sequência de conteúdos da Bioquímica é grande e "pesada". Os professores demonstravam preocupação em trabalhar tudo, especialmente (na Bioquímica I) Carboidratos, Lipídios e Proteínas; e seu metabolismo (na Bioquímica II).

Um das licenciandas, matriculada nesta disciplina, faz suas considerações sobre suas percepções da Bioquímica: 
Bio - grafia. Escritos sobre la Biología y su Enseñanza. ISSN 2027

Edición Extraordinaria. p.p. 1102- 1112

Memorias del VIII Encuentro Nacional de Experiencias en Enseñanza de la Biología y la Educación Ambiental. III Congreso Nacional de Investigación en Enseñanza de la Biología.

$\mathrm{Na}$ Bioquímica II foi utilizado o mapa metabólico, previamente preparado pelas professoras. Através dele era possivel entender todos os processos e visualizá-los dentro da célula (servia como um esquema visual). Como acadêmica do curso de Ciências Biológicas, tendo também a possibilidade de me aprofundar nas outras áreas do conhecimento biológico sinto que a bioquímica não percorra também no Ensino Médio os outros conteúdos da Biologia, a fim de que os alunos pudessem compreendê-lo de maneira completa. Entendo que tudo o que acontece dentro de uma célula envolve eventos bioquímicos (docente em formação inicial).

Esses argumentos podem representar avanços para a qualidade do ensino na educação básica, visto que estes licenciandos estão se constituindo professores com visões diferentes daquelas vivenciadas por eles até então. Krasilchik \& Trivelato destaca que as práticas curriculares nas escolas parecem bastante comprometidas com uma abordagem reducionista, particularmente com relação ao estudo do corpo humano. Esse corpo, que é "dividido e compartimentalizado para que possa caber no ensino, vai se apresentando em aspectos funcionais, celulares e moleculares, por uma forte tradição curricular que se expressa em organização de tópicos, em ilustrações, esquemas, equações etc."(KRASILCHIK \&TRIVELATO, 2005 p. 127)

A partir da proposta do PPC constrói-se o plano de ensino em que são explicitados os modos de trabalhar as disciplinas, bem como o processo avaliativo.

As aulas são desenvolvidas contemplando teoria e prática de modo articulado. São realizados experimentos em laboratório que servem como instrumento de investigação e reflexão sobre diferentes temáticas abordadas, bem como subsídios para compreender os conceitos complexos, abordados no componente curricular de Bioquímica I. É realizado um seminário apresentado em grupo $e$ envolvendo temáticas de interesse de cada grupo de alunos. São usados Software, vídeos e outros recursos possíveis e necessários para construção de uma aprendizagem efetiva (Plano de Ensino de Bioquímica I).

As aulas expositivas serão ministradas de modo interativo possibilitando a construção de conceitos de bioquímica. Haverá 
Bio - grafia. Escritos sobre la Biología y su Enseñanza. ISSN 2027

Edición Extraordinaria. p.p. 1102- 1112

Memorias del VIII Encuentro Nacional de Experiencias en Enseñanza de la Biología y la Educación Ambiental. III Congreso Nacional de Investigación en Enseñanza de la Biología.

realização de seminários, utilização de vídeos e outros recursos possíveis e necessários a uma aprendizagem efetiva. Para melhor compreender o metabolismo será construído um mapa metabólico, caracterizando cada grupo de substâncias que constituem os seres vivos (Plano de Ensino de Bioquímica II).

Verifica-se que existe preocupação com a diversidade de recursos metodológicos, e com a dinâmica de condução das aulas, que tem como base o referencial histórico cultural com sua centralidade em Vigotski (2000). O autor defende a formação de conceitos a partir de diferentes contextos e que as interações sociais permitem a internalização de significados mais complexos, já que as primeiras ideias sobre as coisas são vistas como elaborações individuais próprias, mas derivadas da internalização das significações inicialmente mediadas e vivenciadas em interação com os outros.

Deste modo, na bioquímica I, inicia-se com a investigação experimental dos constituintes da matéria viva e suas interações com o meio. Na medida em que se usa a palavra em cada aula ela vai ganhando um novo sentido e significado mais complexo. Assim, a cada novo conceito, que se pretende significar, utiliza-se um contexto diferente, que possibilite a problematização e produção de diferentes significados. $\mathrm{Na}$ bioquímica II, a conceitualização inicia com a análise dos alimentos ingeridos durante um dia, perfazendo o caminho de visualização do alimento em si, sua constituição, como é digerido, como é absorvido e finalmente o que acontece com os nutrientes em nível celular. Assim, o metabolismo é discutido sempre por meio de interrelações entre as diferentes rotas metabólicas e a permanente problematização das necessidades biológicas em diferentes situações do cotidiano dos seres vivos.

Outro aspecto relevante refere-se aos conhecimentos bioquímicos nos livros do ensino superior e médio. A análise de alguns dos livros indicados nas referências permite visualizar algumas das constituições dos conhecimentos específicos articulados com os saberes docentes produzidos na formação profissional. Nos livros didáticos, usados no ensino superior "Bioquímica" de Valter T. Motta (2005) e "Princípios de Bioquímica" de Albert L. Lehninger et al. (2000, $2^{a}$ impressão), observa-se que apenas no segundo deles são abordados os aspectos históricos relacionados às descobertas e produções da Bioquímica. O livro de Motta (2005) traz os conteúdos de maneira bastante objetiva e tem uma linguagem química marcante. Já o texto de Lehninger et al. (2000, $2^{a}$ impressão) oportuniza ao acadêmico a relação histórico-social com os conteúdos. Um exemplo seria os estudos de Carolus Linneaeus e Charles Darwin, em que é referenciado o reconhecimento 
Bio - grafia. Escritos sobre la Biología y su Enseñanza. ISSN 2027

Edición Extraordinaria. p.p. 1102- 1112

Memorias del VIII Encuentro Nacional de Experiencias en Enseñanza de la Biología y la Educación Ambiental. III Congreso Nacional de Investigación en Enseñanza de la Biología.

das semelhanças e diferenças anatômicas entre os organismos vivos, feita por Linneaeus. Isto constituiu uma base para estudar as relações das diversas espécies de seres vivos. Darwin, segundo Lehninger et al (2000 p.13) "deu-nos a hipótese unificadora para explicar a filogenia dos organismos - a origem das espécies". Ainda, destaca que a bioquímica começou a revelar a anatomia molecular das células de várias espécies. Neste sentido, o livro didático de Lehninger et al $\left(2000,2^{a}\right.$ impressão) retrata mais amplamente este foco histórico. Os exemplos perpassam grande parte dos conteúdos. Esse aspecto mesmo não aparecendo em destaque no programa da disciplina, é abordado em sala de aula, portanto o plano de ensino, na forma expressa nem sempre reflete todas os aspectos tratados em sala de aula.

O livro didático de Biologia do Ensino Médio, usado em todas as escolas da rede pública estadual de Panambi (RS) - "Biologia" de Linhares \& Gewandsznajer (2008), tem uma abordagem bastante resumida acerca dos conceitos sem apresentar qualquer relação com os aspectos históricos da Bioquímica. O seu texto aborda a história da descoberta da célula, denominada pelo inglês Robert Hooke, em 1665. Uma narrativa breve e sintética situa $o$ estudante inicialmente, para logo em seguida retratar o tamanho e a forma das células. Também resume o prêmio Nobel de Fisiologia e Medicina recebido em 1962 por Francis Crick e James Watson, que propuseram o modelo de dupla hélice para a estrutura do DNA. Todos os componentes químicos da célula, da respiração celular e da fotossíntese não são abordados com um contexto histórico, e sim com descrições das estruturas moleculares, processos envolvidos, resultados de energia liberada, entre outros conhecimentos específicos.

\section{Algumas considerações}

A pesquisa mostra que uma forma diferente de abordar o ensino de bioquímica é a possibilidade de reflexão dos licenciandos sobre suas vivências durante a graduação, reconhecendo formas de ensino contextualizadas, com a preocupação de produzir sentidos e significados para seu estudo, melhorando assim a atuação na educação básica. Mesmo que os livros didáticos apresentem sequências de conteúdos lineares e fragmentadas, a formação docente crítica permite que estes utilizem formas diversificadas de ensino de modo a também propiciar aos seus alunos capacidade reflexiva responsável. Além disso, 0 curso de biologia, em discussão, ao contemplar em seu projeto político pedagógico, momentos de reflexão sobre a trajetória de formação dos professores, como sistematização do curso, possibilita a produção de novos sentido e significados ao fazer docente em formação. 
Bio - grafia. Escritos sobre la Biología y su Enseñanza. ISSN 2027

Edición Extraordinaria. p.p. 1102- 1112

Memorias del VIII Encuentro Nacional de Experiencias en Enseñanza de la Biología y la Educación Ambiental. III Congreso Nacional de Investigación en Enseñanza de la Biología.

\section{REFERÊNCIAS}

BRASIL. Lei de Diretrizes e Bases da Educação Nacional. Lei 9394/96 de 20 de dezembro de 1996.

BRASIL (2006) Parâmetros Curriculares Nacionais Mais

KRASILCHIK, Miriam \& TRIVELATO, Sílvia (coord.) 1995 Biologia para o cidadão do Século XXI. São Paulo: FEUSP. 250 p.

LEHNINGER, A. L.; NELSON, D. L. \& COX, M.M. 2000 Princípios de bioquímica. 2a Ed. São Paulo: Ed. Sarvier, 2000. 839p.

LINHARES, S. \& GEWANDSZNAJER, F. (2008) Biologia, Editora Ática

MOTTA, Valter T. (2005) Bioquímica. São Paulo, Editora: Educs

UNIJUÍ. Projeto Politico Pedagógico. Curso de Licenciatura em Ciências Biológicas. 2007.

VIGOTSKI, Lev Semenovich. A construção do pensamento e da linguagem. São Paulo: Martins Fontes, 2000. 